\title{
Coarctation of the aorta in infancy and childhood
}

\author{
E. A. Shinebourne, A. S. Y. Tam, A. M. Elseed, M. Paneth, S. C. Lennox, W. P. Cleland, \\ C. Lincoln, M. C. Joseph, and R. H. Anderson ${ }^{1}$ \\ From the Departments of Paediatrics and Surgery, Brompton Hospital and Cardiothoracic Institute, London
}

The management and results of treatment in 181 children with coarctation of the aorta are presented. In this series, 79 per cent of the patients presented in the first year of life and 55 per cent presented as neonates. One hundred and fifty patients were operated on, with a total surgical mortality of 21 per cent. Only one surgical death occurred in those operated on after 3 months of age. The higher mortality in young infants is closely related to associated cardiac anomalies and to the frequency of aortic and isthmal hypoplasia. Our findings suggest that neonates presenting with heart failure and coarctation should be operated on early, as the surgical mortality under 6 weeks is 45 per cent, whereas there is an 86 per cent mortality in neonates who were not operated on. Analysis of follow-up indicates that when operation can be performed electively the optimal period for surgical treatment is between 6 months and 1 year of age. If operation is performed after this age, there may be persistent systemic hypertension despite relief of aortic obstruction.

Coarctation of the aorta is one of the commonest congenital cardiovascular anomalies in infancy and childhood (Keith, Rowe, and Vlad, 1967). It is a common cause of early heart failure (Rowe and Mehrizi, 1968) and was the fifth most frequent cardiac anomaly in one series of 500 infants undergoing cardiac surgery in the first year of life (Cooley and Hallman, 1964). However, the optimal time for operation is by no means established. When congestive heart failure is a complicating factor during infancy it can be argued that immediate relief of the obstruction is a necessity. In the absence of heart failure the decision regarding timing of surgery is more difficult, since resection in infancy poses considerable technical problems, and it is known that some patients may develop recurrent coarctation. In order to provide data pertinent to this problem we have reviewed the results of management of 181 infants and children with coarctation seen at the Brompton Hospital in the 7-year period between January 1967 and December 1973.

\section{Patients studied}

Altogether 181 patients were studied in whom the diagnosis of coarctation of the aorta had been confirmed

Received 31 October 1975.

1R.H.A. is a British Heart Foundation Senior Research Fellow. by either cardiac catheterization and angiocardiography, surgery, or necropsy Their ages ranged from 1 day to 14 years, with a male:female ratio in the whole series of $1 \cdot 7: 1$. When coarctation was considered as an isolated condition this ratio was $2 \cdot 6: 1$. In contrast, coarctation with associated cardiac anomalies gave a male:female ratio of $1 \cdot 1: 1$.

During this period two patients have been seen in whom coarctation was associated with right aortic arch; these have been reported separately (Honey et al., 1975) and are not included in this series.

\section{Clinical presentation}

The mode of presentation in four age groups is shown in Table 1.

\section{Associated anomalies}

Associated cardiac anomalies, which profoundly influence mode of presentation, were commoner in the younger infants (Table 2). Thus 84 per cent of patients under 1 week and 86 per cent of patients up to 4 weeks had major cardiac anomalies in contrast to 52 per cent of patients between 4 weeks and 1 year of age and 27 per cent of patients over 1 year. It should also be noted that the patients presenting as neonates had more complex anomalies, either cyanotic or acyanotic, than those presenting after this time. 
TABLE 1 Mode of presentation of coarctation of aorta

\begin{tabular}{|c|c|c|c|c|}
\hline & $<1 w k$ & $\begin{array}{l}1 w k- \\
4 w k\end{array}$ & $\begin{array}{l}4 w k- \\
1 y r\end{array}$ & $1-14 y r$ \\
\hline Total number & 55 & 44 & 44 & 38 \\
\hline Heart failure & 35 & 30 & 18 & 1 \\
\hline Cyanosis + heart failure & 11 & 7 & 2 & 0 \\
\hline Cyanosis & 4 & 0 & 0 & 0 \\
\hline Swollen feet & 1 & 0 & 0 & 0 \\
\hline Failure to thrive & 0 & 1 & 2 & 0 \\
\hline Asymptomatic & 4 & 6 & 22 & 37 \\
\hline
\end{tabular}

\section{Diagnosis}

Clinical recognition of coarctation depended upon the finding of absent or decreased femoral pulses in all cases. A difference in systolic blood pressure measurements between upper and lower limbs of greater than $30 \mathrm{mmHg}(4.0 \mathrm{kPa})$ was taken as confirmatory evidence of the diagnosis. Over the past two years blood pressure measurements have been recorded using a Doppler shift technique which has been shown to give accurate and reproducible results (Elseed, Shinebourne and Joseph, 1973). Pressure differences of up to $30 \mathrm{mmHg}(4.0 \mathrm{kPa})$ between the upper and lower limbs are commonly found in the normal neonate (de Swiet, Peto, and Shinebourne, 1974), and hence have been disregarded. In the majority of instances cardiac catheterization and angiography were performed. In broad terms the angiographic appearances showed the obstruction to be either a discrete juxtaductal coarctation or more widespread aortic and isthmal hypoplasia (Rudolph, Heymann, and Spitznas, 1972; Shinebourne and Elseed, 1974; Elseed, Shinebourne, and Paneth, 1974). While it is realized that these different types are probably distinct pathophysiological entities, for the purposes of this presentation they have been grouped together as 'coarctation'.

\section{Management}

All patients who were admitted to hospital in heart failure were treated with appropriate therapy and in the majority cardiac catheterization was undertaken.

Thirty-five of the 55 neonates presenting in the first week of life had resection of coarctation within the first 6 weeks of life and 12 died before operation could be performed. Five patients had delayed operations, one being performed at 2 months, one at 9 months, and three after 1 year. Three patients had no operation because the gradient between brachial and femoral systolic pressures was small, barely exceeding that found in the normal neonate (de Swiet et al., 1974). Operations were performed on 38 of 44 neonates presenting between 1 week and 4 weeks of age, 25 before 6 weeks, 10 before a year, and 3 after this time. Six patients in this group died before operation could be carried out. Of the 44 infants who were seen between 4 weeks and 1 year, 21 were operated upon before and 17 after 1 year; 6 patients were not operated upon because of minor coarctation. In the 38 children who were older than 1 year at presentation, 24 were operated upon within 1 year of referral and 10 in the subsequent years; the age at operation ranged from 2 to 16 years. Four patients were not operated upon as the coarctation was mild. Fig. 1 relates surgical mortality to age at the time of operation.

\section{Complications of surgery}

Operations were performed on $150(82 \%)$ of the 181 patients. Of these, $27(18 \%)$ died within 48 hours of

TABLE 2 Associated cardiac anomalies in 181 patients with coarctation of aorta

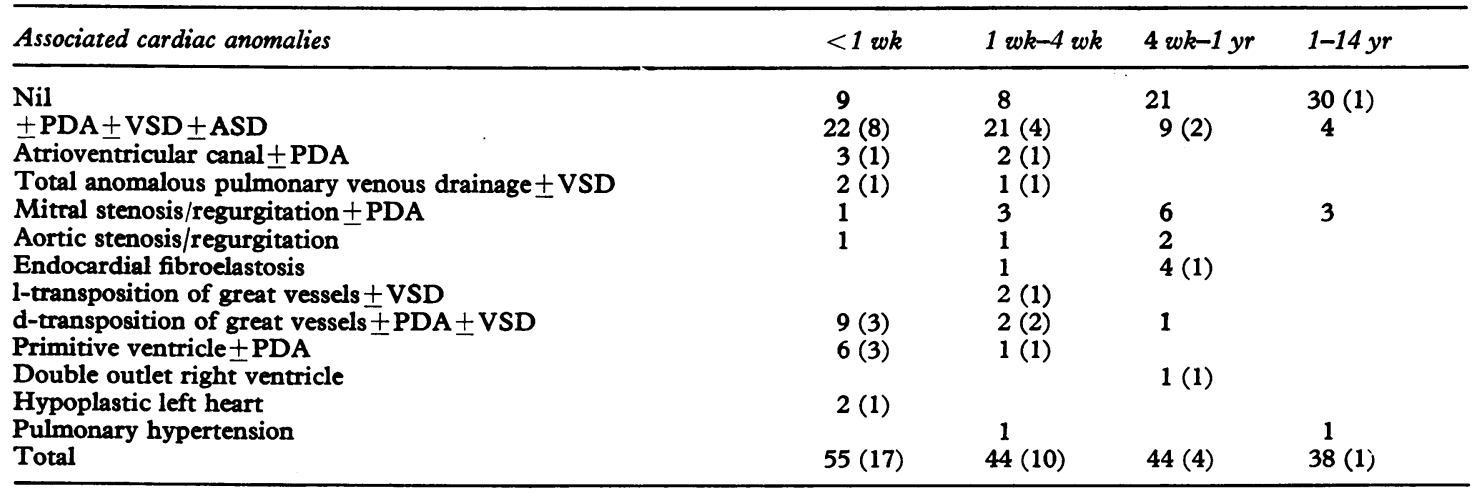

Note: Figures in parentheses indicate all operative and postoperative deaths. PDA, persistent ductus arteriosus; VSD, ventricular septal defect; ASD, atrial septal defect. 


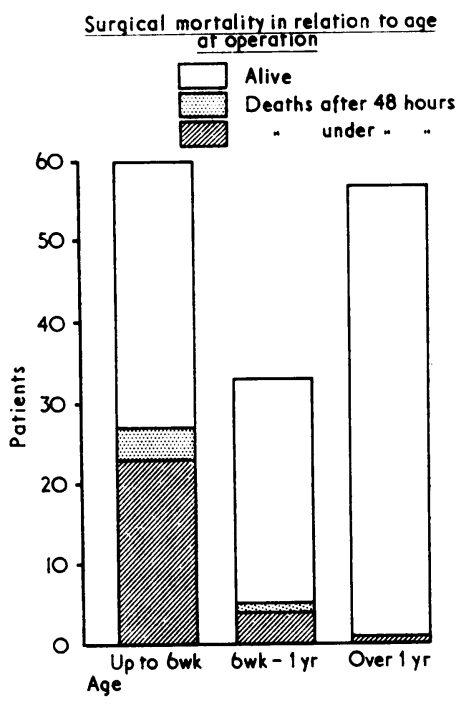

FIG. 1 Surgical mortality according to age at operation. Note that of deaths under 48 hours in group between 6 weeks and 1 year, only one patient died over age of 3 months.

operation. There were five deaths after 48 hours. Of these, one could be attributed to the presence of associated endocardial fibroelastosis, one to uncontrollable heart failure and jaundice with suspected septicaemia; one infant died 3 days after operation as a result of severe preoperative acidosis, and in the remaining two cases, death occurred two weeks after operation from unknown causes. Thus, the overall surgical mortality was 21 per cent. Analysis within the age-groups at surgery indicated that the majority who died were under 6 weeks of age (27 of the 32 who died) (Fig. 1). A high proportion of these patients had serious associated cardiac anomalies (Table 2). Between 6 weeks and 1 year of age (33 patients operated) there were four operative and postoperative deaths $(12 \%)$. After 1 year of age (57 patients operated) only one patient died after operation, a girl whose aorta ruptured in the immediate postoperative period.

Thirty-one patients with proven coarctation did not undergo operation. Of 15 under 1 week, 12 died, and of these nine had severe associated cardiac anomalies. Birth injury, hypothermia, or profound acidosis on admission contributed to death, but seven patients died while the accompanying heart failure was being treated medically. Six patients presenting between 1 and 4 weeks died before operation could be performed, five of these having associated anomalies. The mortality in patients presenting as neonates in whom no operation was performed was therefore 86 per cent. Of the 38 patients who, in the first year of life, were found to have isolated coarctation, 12 presented in heart failure, 10 had immediate operations, with only one death. Our present policy, therefore, is to operate upon all patients with heart failure accompanying coarctation. All the patients presenting above the age of 1 month who were not operated on had coarctation of minor degree and all survived.

\section{Postoperative results of surgery}

Patients' data were included only if they were followed for a period of at least 6 months. Eightyseven patients satisfied this criterion, and of these 24 had their coarctations resected in the first 6 weeks of life and 22 in the period between 6 weeks and 1 year of age. The follow-up periods after operation in the first year were up to 5 years (Fig. 2), with a mean of $2 \cdot 2$ years. The 41 patients operated upon after 1 year had a follow-up period ranging from 6 months to 10 years (Fig. 3), with a mean of $2 \cdot 7$ years. Many of our patients had been referred from other countries, or other centres, thus accounting for the proportionately small number of patients with longterm follow-up data.

In Fig. 2 and 3 upper limb blood pressure at the last follow-up has been compared with the normal

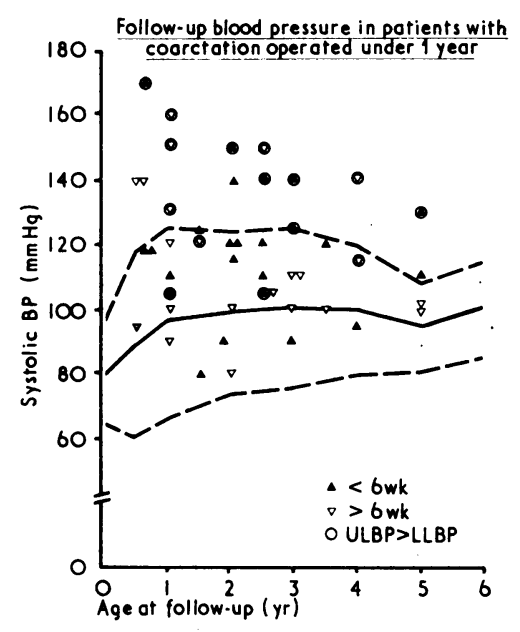

FIG. 2 Follow-up systolic blood pressure in patients with coarctation operated upon under 1 year of age. $\Delta<6$ weeks; $\nabla>6$ weeks; $\bigcirc$ upper limb systolic blood pressure $>$ lower limb systolic blood pressure. Normal systolic blood pressure (mean $\pm 2 S D$ ) is shown by continuous and dashed lines (Master et al., 1950; Nadas and Fyler, 1972). Of 14 patients whose follow-up blood pressure was abnormally high, 10 had diminished femoral pulses. $1 \mathrm{mmHg} \approx 0.133 \mathrm{kPa}$. 


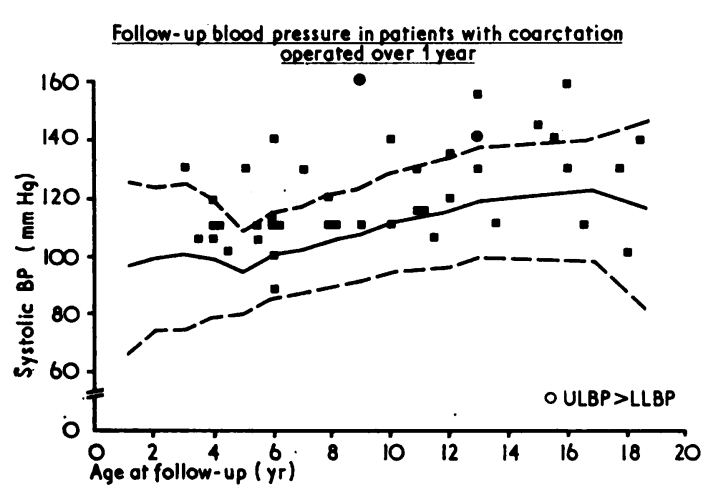

FIG. 3 Follow-up systolic blood pressure in patients with coarctation operated upon over the age of 1 year. O upper limb systolic blood pressure > lower limb systolic blood pressure. Thirteen patients are seen to have abnormally high systolic pressures but in only 2 were femoral pulses diminished. $1 \mathrm{mmHg} \approx 0.133 \mathrm{kPa}$.

blood pressure for age (Master, Dublin, and Marks, 1950; Nadas and Fyler, 1972). Where there was a discrepancy between the upper and lower limb blood pressure, either by direct measurement or by palpation, this has been indicated on the figures. Of the 24 patients operated on before 6 weeks of age, 29 per cent had a blood pressure above the normal range ( 7 patients); of the 22 patients operated upon between 6 weeks and 1 year, the corresponding figure was 32 per cent ( 7 patients). Thirteen of the 41 patients $(32 \%)$ operated upon when over 1 year of age had a raised follow-up blood pressure. When the data were analysed further, it was found that the majority (10 to 14) of infants operated upon under a year had upper limb hypertension associated with diminished femoral pulses. In contrast, of the 13 patients operated after 1 year, only two of those with upper limb hypertension had diminished femoral pulses (or decreased lower limb blood pressures). Thus, 11 of 13 patients whose upper limb blood pressures were greater than 2 standard deviations above the mean had normal femoral pulses. In those where lower limb blood pressure was measured (by the Doppler technique), a raised lower limb pressure was found.

Thus far, six patients have required reoperation, five having had their first resection performed during the first 6 weeks of life. The remaining patient had her first resection at 6 years of age. The age at reoperation ranged from 3 weeks to 9 years, and there was no mortality.

\section{Discussion}

We have presented an analysis of the results of treatment of 181 infants and children referred to our hospital with isthmal hypoplasia or discrete coarctation of the aorta. Our data indicate that a high proportion of neonates and young infants presented in heart failure, making immediate surgery essential. Our earlier experience showed that if operation were not performed in the presence of heart failure, then death was inevitable. Many of the patients presenting in infancy had the isthmal narrowing variety of coarctation. It is now well established that this anomaly reflects reduced aortic flow during intrauterine development (Rudolph et al., 1972; Shinebourne and Elseed, 1974; Elseed et al., 1974): this fact itself usually indicates the presence of additional intracardiac anomalies. Taking into account, therefore, that coarctation is only part of the overall anomaly, the surgical mortalities of 45 per cent below the age of 6 weeks and 12 per cent for patients operated on between 6 weeks and 1 year are not discouraging. The overall mortality in infancy of 31 per cent compares favourably with previous reports, which cite mortalities in infancy from 21 to 56 per cent (Mortensen et al., 1959; Glass, Mustard, and Keith, 1960; Hallman et al., 1967; Tawes et al., 1969; Sinha et al., 1969). We were able to judge the efficacy of the operation in 24 of the 60 patients who had their operation in the first 6 weeks of life and who were followed up for at least 6 months. We found that 30 per cent of these patients had residual hypertension. The feature of the data from this group was that upper limb pressures were increased while lower limb pressures were decreased. This suggests that the hypertension resulted from incomplete removal of the hypoplastic aortic segment, and it is significant that five of the six patients requiring reoperation were in this age group. It may also be relevant that further analysis showed that of the 14 patients with pressure differentials after operation, 13 had been severely ill at the time of operation and a rapid operative procedure had been essential. These findings agree with those of Rathi and Keith (1964), who reported 150 children of whom 27 had their coarctation resected in infancy; they too found 30 per cent in this group with upper limb hypertension and reduced lower limb pressures.

When we critically analyse those of our patients referred as infants, that is between the ages of 1 month and 1 year, we find that only 18 of 44 presented with heart failure. This lower proportion compared with neonates undoubtedly reflects a smaller number of patients with aortic isthmal hypoplasia secondary to intracardiac anomalies. As 
would be expected in a group of patients with larger hearts and requiring less complicated operations, the operative mortality was also considerably reduced $(12 \%)$ when operations were performed between 6 weeks and 1 year of age. Furthermore these operative deaths all occurred in patients below the age of 3 months. Twenty-two of the patients were followed up postoperatively and seven had residual hypertension. As with the neonatal group, the pattern of hypertension was for the upper limb pressure to be higher than that in the lower limbs. It seems reasonable to suggest again that these findings reflect incomplete resection of the hypoplastic aortic segment.

The trend of presentation discussed above is continued in our patients above 1 year of age. Thus, only one of 38 patients presented in cardiac failure, and as may be deduced, the greater majority of these patients had isolated juxtaductal coarctation. When operation was performed above 1 year of age, the surgical mortality was, again as expected, considerably lower. Of our 57 patients operated upon above the age of 1 , all but one survived. However, it was disturbing to find that 13 of these patients had a raised blood pressure at follow-up. This figure of 23 per cent may be compared with the 30 per cent with residual hypertension in our infantile group. In contrast to this infantile group, most of the older patients had increased lower limb pressures and normal femoral pulses, only 2 of the 13 showing a pressure differential between the upper and lower limbs. Thus, these older patients, several of whom were operated upon under the age of 5 years, showed evidence of systemic hypertension. Rathi and Keith (1964) found that only 20 per cent of their patients operated on over the age of 1 year had residual hypertension, and half of these had pressure differentials between the limbs. Our findings are clearly at variance with these figures, but it must be stated that others have reported persistent systemic hypertension after resection of coarctation (Maron et al., 1973; James and Kaplan, 1974). The study of James and Kaplan (1974) is particularly noteworthy, since they found that of 14 patients operated on between 6 and 16 years of age, 11 had resting systolic blood pressures greater than the 90th centile, the pressures rising to considerably higher levels on exercise.

Thus, our investigation indicates that the increased mortality from early operation must be set against the risk of development of systemic hypertension if operation is deiayed. We believe that our findings show that immediate operation is essential when 'complicated' coarctation is encountered in infancy. When operation can be performed as an elective procedure, we suggest that our data indicate the best time for operation to be in the second half of the first year of life. As a corollary to this, we would also suggest that it is important to diagnose coarctation of the aorta within the first year of life, since delay in operation may result in the development of persisting systemic hypertension.

We thank all our colleagues at the Brompton Hospital who have assisted in the diagnosis and care of our patients. We are particularly indebted to Dr. G. A. H. Miller and Dr. K. F. W. Hinson. Dr. Tam was supported by a grant from the Hong Kong Government.

\section{References}

Cooley, D. A., and Hallman, G. L. (1964). Surgery during the first year of life for cardiovascular anomalies. A review of 500 consecutive operations. Fournal of Cardiovascular Surgery, 5, 584.

de Swiet, M., Peto, J., and Shinebourne, E. A. (1974). Difference between upper and lower limb blood pressure in normal neonates using Doppler technique. Archives of Disease in Childhood, 49, 734.

Elseed, A. M., Shinebourne, E. A., and Joseph, M. C. (1973). Assessment of techniques for measurement of blood pressure in infants and children. Archives of Disease in Childhood, 48, 932.

Elseed, A. M., Shinebourne, E. A., and Paneth, M. (1974). Manifestation of juxtaductal coarctation after surgical ligation of persistent ductus arteriosus in infancy. British Heart Fournal, 36, 687.

Glass, I. H., Mustard, W. T., and Keith, J. D. (1960). Coarctation of the aorta in infants. A review of twelve years' experience. Pediatrics, 26, 109.

Hallman, G. L., Yashar, J. J., Bloodwell, R. D., and Cooley, D. A. (1967). Surgical correction of coarctation of the aorta in the first year of life. Annals of Thoracic Surgery, 4, 106.

Honey, M., Lincoln, J. C. R., Osborne, M. P., and de Bono, D. P. (1975). Coarctation of aorta with right aortic arch. Report of surgical correction in 2 cases: one with associated anomalous origin of left circumflex coronary artery from the right pulmonary artery. British Heart fournal, 37, 937.

James, F. W., and Kaplan, S. (1974). Systolic hypertension during submaximal exercise after correction of coarctation of aorta. Circulation, 50, Suppl. II, 27.

Keith, J. D., Rowe, R. D., and Vlad, P. (1967). Heart Disease in Infancy and Childhood, 2nd ed. p. 213. Macmillan, New York.

Maron, B. J., Humphries, J. O'N., Rowe, R. D., and Mellits, E. D. (1973). Prognosis of surgically corrected coarctation of the aorta: a 20 year postoperative appraisal. Circulation, 47, 119.

Master, A. M., Dublin, L. I., and Marks, H. H. (1950). The normal blood pressure range and its clinical implications. fournal of the American Medical Association, 143, 1464.

Mortensen, J. D., Cutler, P. R., Rumel, W. R., and Veasy, L. G. (1959). Management of coarctation of the aorta in infancy. Fournal of Thoracic and Cardiovascular Surgery, 37, 502.

Nadas, A. S., and Fyler, D. C. (1972). Pediatric Cardiology, p. 665. W. B. Saunders, Philadelphia.

Rathi, L., and Keith, J. D. (1964). Post-operative blood pressures in coarctation of the aorta. British Heart fournal, 26, 671 . 
Rowe, R. D., and Mehrizi, A. (1968). The Neonate with Congenital Heart Disease, p. 127. W. B. Saunders, Philadelphia.

Rudolph, A. M., Heymann, M. A., and Spitznas, U. (1972). Hemodynamic considerations in the development of narrowing of the aorta. American fournal of Cardiology, $30,514$.

Shinebourne, E. A., and Elseed, A. M. (1974). Relation between fetal flow patterns, coarctation of the aorta, and pulmonary blood flow. British Heart fournal, 36, 492.
Sinha, S. N., Kardatzke, M. L., Cole, R. B., Muster, A. J., Wessel, H. J., and Paul, M. H. (1969). Coarctation of the aorta in infancy. Circulation, 40, 385.

Tawes, R. L., Aberdeen, E., Waterston, D. J., and BonhamCarter, R. E. (1969). Coarctation of the aorta in infants and children. A review of 333 operative cases, including 179 infants. Circulation, 39 and 40, Suppl. I, 1-173.

Requests for reprints to Dr. E. A. Shinebourne, Brompton Hospital, Fulham Road, London SW3 6HP. 